\title{
Exploring value creation and appropriation in the reverse clothing supply chain
}

Erik Sandberg, Rudrajeet Pal and Jukka Hemilä

The self-archived postprint version of this journal article is available at Linköping University Institutional Repository (DiVA):

http://urn.kb.se/resolve?urn=urn:nbn:se:liu:diva-145320

N.B.: When citing this work, cite the original publication.

Sandberg, E., Pal, R., Hemilä, J., (2018), Exploring value creation and appropriation in the reverse clothing supply chain, International Journal of Logistics Management, 29(1), 90-109.

https://doi.org/10.1108/IJLM-10-2016-0241

Original publication available at:

https://doi.org/10.1108/IJLM-10-2016-0241

Copyright: Emerald

http://www.emeraldinsight.com/ 


\title{
Exploring value creation and appropriation in the reverse clothing supply chain
}

\begin{abstract}
Purpose: The purpose of this paper is to explore the processes of value creation and appropriation among companies in a reverse clothing supply chain.

Design/methodology/approach: This research is based on an inductive case study approach at fashion retailers, charity organisations, commercial recyclers, and specialised sorting companies involved in take back schemes for used clothes in the reverse clothing supply chain.

Findings: Value creation and appropriation processes are illustrated for different members of the reverse clothing supply chain. Capture of different types of value and value co-creation explain the relatively high degree of collaboration among members in the "beginning" of the reverse supply chain. Here, collaboration outmanoeuvres the traditional value appropriation mechanism of price negotiation.
\end{abstract}

Research limitations/implications: This research does not cover all tiers in this global industry, and practices among different regions may hamper the generalizability of the findings presented.

Practical implications: This research allows a comprehensive picture of the members in the reverse clothing supply chain and outlines some of the major processes involved, decisive for value creation and appropriation.

Originality/value: The research draws upon the value concept and combines processes of value creation and appropriation in one, single empirical study. By doing that, the research disseminates the reverse clothing supply chain in a new way and facilitates improved understanding of the structure and rationales for members taking part in it.

Key words: value creation, value appropriation, reverse supply chain, clothing, case study

Article classification: Research paper

\section{Introduction}

In accordance with improved efforts towards environmental sustainability among end consumers as well as society in general there has been an increased interest in reverse clothing practices among practitioners as well as academics (Brooks, 2013; Hvass, 2014; 0’Reilly \& Kumar, 2016). Inspired by other industries, in which regulations for extended producer responsibility have forced manufacturers to take a life-cycle approach to their products and manage the reverse handling of these (e.g. Fleischmann et al., 2004; 
Jayaraman \& Luo, 2007; Hvass, 2014), many fashion retailers have taken similar initiatives, often together with partner companies such as charity organisations.

The reverse clothing supply chain consists of a complex, global network of members, including fashion retailers and charity organisations, but also commercially oriented international recyclers and specialised sorting companies at different tiers in the supply chain (Brooks, 2013; O'Reilly \& Kumar, 2016). Through a series of complex reverse activities, typically including acquisition, grading, re-processing, and re-distribution (Fleischmann et al., 2004), waste clothes are recharged with new value for new purposes and customers. The customers to this "new" supply chain typically range from high-street vintage clothes customers to charity receivers. In addition, retailers and their manufacturers also become customers to the reverse clothing supply chain as recycled textile fibres are increasingly included as raw material in new products.

In recent years it has been recognised that the reverse supply chain offers opportunities for value creation among its members (Jayaram \& Luo, 2007). Aspects such as improved customer satisfaction (Skinner et al., 2008; Fleischmann et al., 2004; Jayaraman \& Luo, 2007; O'Reilly \& Kumar, 2016), improved brand image (Jayaraman and Luo 2007; Fleischmann et al. 2004), information about end customer demands and behaviour (Bernon et al., 2011; Jayaraman \& Luo, 2007), and access to recycled raw material (Hvass, 2014) are suggested in literature. However, so far there is little in-depth analysis and empirical evidence on the value creation in reverse supply chains (Schenkel et al., 2015; Bernon et al., 2011). This is valid also for the reverse clothing supply chain, which here forms an interesting, information-rich empirical basis to the research.

As in other industries, value creation processes have so far been discussed at a superficial level, despite their obvious importance for the existence of, and rationale behind, reverse clothing supply chains. In addition, the value appropriation among different supply chain members, i.e. how the value created is captured among involved supply chain members, is not well understood (Brooks, 2013). Therefore, as a means to better understand the reverse clothing supply chain, the purpose of this paper is to explore the processes of value creation and appropriation among companies in a reverse clothing supply chain.

Value creation as well as value appropriation can be addressed at different levels of analysis (Lepak et al., 2007). For the purpose of this paper, the focus is on the organisational level, i.e. the involved companies in the reverse supply chain. Based on interviews and other field observations at Swedish fashion retailers, Nordic charity organisations, international commercial recyclers, and Indian specialised sorting companies, this paper explores the processes of value creation and appropriation involved in the take back scheme ${ }^{1}$ for used clothes. For practitioners it allows a comprehensive picture of the members in the reverse clothing supply chain and the major processes involved. Theoretically, the research draws upon the value concept and combines the processes of value creation and appropriation in one, single empirical study. By doing that, the research disseminates the reverse clothing supply chain in a new way and facilitates improved understanding of the structure and rationales for members taking part in it.

\footnotetext{
${ }^{1}$ The term "take back scheme" may be given slightly different interpretations in different industries. In the fashion industry context as adressed in this research, a take back scheme is a voluntary-based programme for collection of used clothes. Involved in the programme are typically retailers and their collaboration partners such as charity organisations.
} 
The remainder of this paper starts with a theoretical overview of value creation and appropriation in the reverse clothing supply chain, and continues with a methodology section in which the research approach is explained. Thereafter findings and analysis in terms of value creation and appropriation at the four types of investigated supply chain members (retailers, charities, commercial recyclers and specialised sorting companies) are presented. Finally, conclusions from the study are drawn and future research areas are developed.

\section{On the value concept in the reverse clothing supply chain}

\subsection{The value concept}

Despite its central role in theory building, the value concept still suffers from a multitude of competing perspectives and theoretical groundings, blurring the core of the concept and making it difficult for practitioners and scholars to grasp. A definition for "value" as a stand-alone term is seldom provided and there is little consensus on other related terms such as value creation (Lepak et al., 2007), value co-creation (Saarijärvi et al., 2013) and value appropriation (Lavie, 2007). There are in particular two features of the value concept that obstructs its clarity; (1) the fact that value is subjectively perceived and understood in the eyes of the receiver, and (2) the multidimensionality of value, i.e. the existence of different types of value beyond economic ones.

A common approach towards clarification of the first matter is to distinguish between use value and exchange value (Bowman \& Ambrosini, 2000; Lepak et al., 2007). Use value can be defined as the customers' (i.e. the buying companies') "perceptions of the usefulness of the product on offer" (Bowman \& Ambrosini, 2000, p. 15). It refers to the specific qualities of the offered product (or service) in relation to the customers' needs and is therefore a subjective measure perceived by the individual customer at a given point of time. In turn, the exchange value refers to monetary price, defined as "the amount paid by the buyer to the seller for the use value" (Bowman \& Ambrosini, 2000, p. 15). Overall, given the understanding of use and exchange value, the customer's perception of the sum of the use value(s) offered, translated into monetary terms, must be higher than the exchange value. Otherwise, there will be no transaction (Lepak et al., 2007).

A second fundamental concern muddling the understanding of the value concept is whether the scope is limited to monetary value only, or if it also includes other values. For instance, value has been framed in the triple bottom line discussion, acknowledging that except for economic values, there are also environmental and social values to consider. These other value types may not be possible to be completely translated into economic ones (Klassen, 2009). Thus, in addition to different perception of values in monetary terms, customers may also perceive and acknowledge other types of values differently.

Schenkel et al. (2015) presented in their systematic literature review three additional generic value categories (except for economic value) that are created through appropriate reverse supply chain operations; environmental value, customer value, and information value. These categories together span tangible as well as intangible values for multiple actors involved in the reverse supply chain, and, as stated by the authors, these values "goes beyond simply generating economic benefits" (Schenkel et al., 2015, p. 7). In brief, environmental value includes the two major categories of (1) environmental performance of green processes and products manifested by e.g. reduction of waste or energy emissions and (2) a green image towards e.g. customers and society in general. Whereas 
the first category is often discussed at a supply chain level, the second is instead associated to a company level. Customer value entails to customer satisfaction and loyalty, achieved by customer service, improved product characteristics and good corporate image. Finally, information value is enhanced when information can improve processes and/or product design. As such, information value can also function as a source for increased other values, i.e. economic, environmental as well as customer values.

Companies are with their limited resources engaged in processes related to creation and appropriation of value (Jayaraman \& Luo, 2007; Mizik \& Jacobsen, 2003) that shape the company's competitive advantage vis-à-vis competitors. Whereas value creation influences the potential magnitude of this advantage, the value appropriation decides the share of the total advantage the company is able to acquire, and the length of time this advantage will persist (Mizik \& Jacobsen, 2003).

The value creation processes consist of "actions of organizational members, who combine to transform the use values that the organization has acquired" (Bowman \& Ambrosini, 2000 , p. 5). Thus, given the distinction between use value and exchange value, companies are involved in creation of use value. In recent years, the concept of "value co-creation" has emerged, acknowledging that value creation is not only an internal matter, but is also conducted in the interaction and/or collaboration among companies ${ }^{2}$. By combining resources and their processes value in production as well as services can be jointly created (Cova et al., 2011). Customers are in this view not to be considered as passive targets. Rather, value is considered as a joint function of value creation mechanisms conducted by the supplier and the customer, and is therefore to be considered as cocreated (Saarijärvi et al., 2013; Cova et al., 2011). After all, the use value that is created is by definition a result of the perceptions of the customer.

As a reverse supply chain incorporate a number of individual organisations that alone or together create value, the question of value appropriation, sometimes referred to as value capture, becomes essential. In order to have a stable, long term reverse supply chain, all involved organisations need to have a value surplus, but the size of the shares could be different. Value appropriation is a function of bargaining power among involved parties (Brandenburger \& Stewart, 1996). The bargaining results in an exchange value, i.e. a price. This price must exceed the perceived opportunity costs at the supplier and be lower than the perceived willingness-to-pay at the customer (Brandenburger \& Stewart, 1996). Thus, the bargaining room could be defined as the space between these two positions, and the price is decided by the bargaining power distribution between the companies (Cox, 1999; Bowman \& Ambrosini, 2000; Rehme et al., 2015). Essentially the more power a supply chain member has relative the other member(s), the more of the value could be appropriated by this supply chain member (Cox, 1999; Bowman \& Ambrosini, 2000). As a basis for a strong bargaining power position, a company needs to have isolation mechanisms to protect the value created (e.g. through an innovation) from being instantly captured by other companies (Cox, 1999; Mizik \& Johansen, 2003). Important isolation mechanisms that can help a company to appropriate value, and built upon a power position, is for instance information asymmetry that may be utilised as a source of power, which in turn results in an advantageous value appropriation. Other important factors discussed are reputation and brand, customer switching costs, and advertising (Mizik \& Jacobsen, 2003) and viable substitute products (Bowman \& Ambrosini, 2000).

2 The concept of value co-creation has several theoretical roots. For an exposé of these, see Saarijärvi et al. (2013). 


\subsection{Value in the reverse clothing supply chain}

Reverse logistics, being an essential ingredient in contemporary efforts towards environmentally friendly closed loop systems, has in recent years got increased research attention. Reverse logistics is typically defined as "The process of planning, implementing, and controlling the efficient, cost effective flow of raw materials, in-process inventory, finished goods, and related information from the point of consumption to the point of origin for the purpose of recapturing or creating value or proper disposal" (Rogers \& TibbenLembke, 1999, p. 2, in Rogers \& Tibben-Lembke, 2001, p. 130). In comparison to other definitions, in which typically environmental aspects are stressed (Carter \& Ellram, 1998), this definition emphasises value creation ${ }^{3}$, an area that is still underexplored in a reverse logistics context (Schenkel et al., 2015).

Carter \& Ellram (1998) introduce a waste hierarchy model to clarify how resource efficient different reverse processes are, i.e. what environmental value the different processes bring. The authors stress that except for resource reduction in the traditional, "forward" supply chain, companies should attempt to maximise reuse activities, followed by recycling activities. As a last option disposal with energy recovery or landfill should be targeted. Except for environmental value, the waste hierarchy goes well in line with how much economic value that could be created in the reverse clothing supply chain. Overall, the reuse option is normally more economically beneficial than that of the other alternatives such as recycling or incineration (Carlsson et al., 2015; Botticello, 2012).

The globally stretched reverse clothing supply chain, focused in this research, normally starts with collection via various channels, e.g. by arranged take-back schemes managed by charities or collaborative networks with other partners (Hvass 2014; Ekström \& Salomonsson 2014; O’Reilly \& Kumar, 2016). In Sweden, the context investigated in this study, second-hand retailers and charity organisations are by far the largest collectors of textiles and clothing, accounting for a yearly per-capita collection of nearly $1.8 \mathrm{~kg}$. This accounts for nearly 16,000 tons being collected yearly (Carlsson et al., 2015). A small portion is also collected by fashion retailers through their recent engagement with instore collection activities. H\&M, for example, one of the largest collectors among them, collected just over 3,000 tons of used clothing (worldwide) in 2014 (Carlsson et al., 2015).

After collection, the clothes are sorted and classified into different categories, based on the level of their dirtiness, i.e. condition, wear and reusability, through a series of processes undertaken by charities, second-hand retailers and/or global sorting firms (Botticello, 2012). Depending on the status of the product returned, and as a part of the process of reclaiming value, the product then undergoes several refurbishing stages such as repairing, washing etc., which is sometimes followed by value adding steps like redesigning and remanufacturing. Once the collected product has passed through collection, sorting, and possibly further steps of remanufacturing, it has regained use value and can re-enter the commodity form and be resold or donated in various

${ }^{3}$ Although Rogers and Timbke (1999) stress recapturing as well as creating value, the difference between these two terms are blurred in their paper. Given Bowman \& Ambrosini's (2000) definition of value creation provided in this paper, i.e. "actions of organizational members, who combine to transform the use values that the organization has acquired", this definition is considered to include recapturing as well as creation of value. 
geographical markets. Botticello (2012) has in her UK-based study highlighted that roughly $20 \%$ of the sorted clothes are resold in the western markets in Europe, while between 50-60\% are exported to Eastern Europe, Africa and Middle East. Remaining volumes are sold as rags or similar, or become incinerated. These proportions are more or less consistent to that in Sweden (Palm et al., 2014).

A crucial determinant for economic value surplus through these processes is cost efficiency due to labour intensity. As claimed by reverse logistics research in general (Skinner et al., 2008; Bernon et al., 2011), of particular importance for such cost efficiency are the grading and sorting processes. Inappropriate grading and sorting processes, that fail to correctly extract maximum value in the waste hierarchy (Carter \& Ellram, 1998), may be costly and hamper the outcome of the value creation process. Thus, without proper capabilities, processes and management of this critical decision point, reverse logistics flow may become a financial burden (Skinner et al., 2008; Jack et al., 2010; Jayaraman \& Luo, 2007).

Going beyond traditional economic values such as cost efficiency, reverse clothing supply chain activities can also enable other values to be created. For instance, customer and environmental values could be attained through environmental efforts. For fashion retailers, awareness-raising activities as a part of post-retail responsibility can be beneficial to get closer to the consumer and engage them in sustainability practices. By doing that, actual environmental performance (explicated in e.g. need for less virgin material) as well as associated environmental image values (perceived by customers) could be enhanced (Hvass, 2014). Hence, while not the donators' efforts are compensated in economic terms, other, socially related benefits may be achieved (O'Reilly \& Kumar, 2016).

\section{Methodology}

\subsection{Research approach}

This explorative research is based on an inductive, qualitative case study approach with multiple data gathering points in the reverse clothing supply chain. In line with previous supply chain management research (e.g. Ellram, 1996; Mollenkopf et al., 2007), such an approach is suitable, given the limited existing research in the area. The intention has been to develop an in-depth understanding of the supply chain members' value creation and appropriation processes, and by that extend the body of existing literature in the area (Ellram, 1996). Except for a mapping of the value and appropriation processes, the research also draws upon these processes and contributes to theory by explaining the rationale for type of relationships that exist in the reverse clothing supply chain. By doing this, the research objective of "fact-finding" is complemented by "good" theory-building research (Wacker, 1998).

The reverse clothing supply chain here constitutes an interesting, information-rich case full of extremes that is valuable for an inductive approach (Flyvbjerg, 2006), and it provides an appropriate ground to extend a theory (Eisenhardt, 1989). Typically, the targeted reverse clothing supply chain include: (1) multiple actor types (profit-making and non-profit, large multi-nationals and small firms), (2) globally stretched over many continents, (3) influenced by differential external factors, e.g. legislations, (4) involves 
different relationships (buyer-seller, donations), and (5) a variety of different types of value created. As such, the chosen supply chain is hence beneficial for exploring relationships and logics essential for theory emergence (Flyvbjerg, 2006).

The reverse clothing supply chain is fragmented when it comes to relationships, and therefore the informants are not all directly connected to each other in long term collaborative relationships. Rather, the targeted supply chain is to a large extent characterised by short-term exchanges, and therefore the empirical data presented in this study should be considered as a case study at an industry level with multiple data points along the different stages of the supply chain.

\subsection{Case selection}

In total, our empirical data collection covers four different categories of supply chain members; fashion retailers, charities, commercial recyclers, and specialised sorting companies. For an overview of the four categories of supply chain members included in the study, see Table 1 below.

\section{Table 1: Overview of types of companies included in the study}

Please insert Table 1 here please

- Among the retailers we have sampled two large Swedish firms considering their volume of operations in the reverse clothing supply chain. They are both wellknown for their efforts in the area, and together they represent well the role of fashion retailers in the investigated supply chain.

- With majority of the used clothes in Sweden being collected by top ten charities, we chose representative organizations for our study from these. Both the charities included in the study rank within first five in terms of collection volume (chosen from Carlsson et al., 2015). They are also relatively similar in terms of business practices and scope of activities regarding the handling of used clothes. Furthermore, they are governed by more or less similar institutional goals, practices and governance structure.

- A snowball approach was pursued in contacting the relevant commercial recyclers. While one of the recyclers included in the study participates in take-back schemes with fashion retailers and holds a major share in Europe in terms of volume of collection (2nd in rank collecting over 90, 000 tons of textile waste per year), the other operates mainly in Scandinavia in collaboration with major charity organizations, collecting over 15,000 tons yearly. Both these organizations export internationally to other customers in Europe and Asia, either as clothes or as recycled materials.

- Further downstream in the reverse clothing supply chain, beyond the western 
European commercial recyclers, specialised sorters in the developing countries are mainly small private firms. The choice of the Indian specialised sorting companies included in this study was motivated by the fact that India ranks as the top importer of worn clothing (importing 4.3\% of global import) (Acharya 2015). A snowball sampling approach was followed due to intercontinental contact difficulties. Initially, we gained contact with 4 large sorting firms before the field visit was organized. During the field visit, due to their close location in one special economic zone, subsequent firms were contacted by gaining acquaintances from the previous ones.

As is shown above, our empirical data collection stretches from a Swedish context in the "beginning" of the reverse clothing supply chain, via western European commercial recyclers, to Indian specialised sorting companies. Major reason for this focus in that in Sweden, similar to most developed countries, the used clothing sector is not mandated by legislative and regulatory policies yet, thus the opportunity for the industrial actors to get involved with value recovery options and create a competitive start is considerably high (Hvass, 2014). This is reflected by the fact that in a sector traditionally involving mainly charities have now seen emergence of major retailers with new business models, e.g. takeback schemes (Hvass, 2014; Watson et al., 2014). Given this industry-drive, and the inherent sustainability-concern of the Swedish fashion industry, diverse values framed under the triple bottom line discussion (e.g. environmental value) is given attention (Watson et al., 2014). However, due to the fragmented supply chain structure and relatively high cost of value adding activities, e.g. sorting (due to high manual labour requirement), the used clothes at a very early stage enters the global network with final destination to developing countries, either for sales as second-hand clothes or for lowcost downcycling, thus leaving the possibility of economic value generation in or near the "country of collection" low (Palm et al., 2014). Overall, this makes the Swedish used clothing chain very fragmented, distributed and complex yet a source of diverse value types - an industry-level case full of extremes, thus serving as a rich contextual setting for exploring the processes of value creation and appropriation.

\subsection{Data collection}

At the four supply chain member categories included in this study in total 14 interviews were held with top decision-making respondents. All respondents were involved in key processes/activities associated with the value creation at their respective companies. From both the fashion retailers we interviewed the sustainability managers who had the best knowhow of the take-back scheme, from the charities and recyclers the operations managers responsible for sorting or recycling facility were interviewed while the owner/managing directors of the small Indian sorting firms were chosen to be our respondent, best suited to our purpose. The interviews can be described as semistructured with open-ended questions (Yin, 2009), particularly covering (1) major activities conducted at each company regarding the flow of used clothes (e.g. sorting, grading, storing, etc.), (2) the rationale involvement in these processes, i.e. strategy and business logic, (3) perceived values related to the undertakings, (4) the position of each company in the reverse supply chain including type of relationships with suppliers and customers. 
In addition to interviews, observations through visits and other documentations such as written reports form the basis for the findings in this study. Regarding field visits, multiple site observations were made in connection to the interviews. Generally, each visit lasted between 1 and 3 hours, depending upon the scale of operation and other practical constraints at the organisation. The field visits allowed the researchers to get a detailed understanding of the firms' reverse supply chain activities, strategies and business logic, and also several key aspects salient to the value mechanisms. Notes were taken during the visits and were aimed at triangulating the information related to the key questions addressed. Conducting the visits just after the interview, provided scope to revisit and verify aspects and concerns from the interview - an informal but effective way to achieve data triangulation. For instance, the manual sorters at the specialised sorting firms were often asked about their key operational requirements when their company strives for a competitive business, which strengthened the view of the specialised sorting companies driven mainly by economic profits. The visits also helped to orientate thoughts and what should be looked for in the next visit and also interviews, as many times the interview transcriptions could not be done before proceeding for the next interview, particularly in case with the specialised Indian sorters as the visits were organised under a limited time period.

When it comes to other documentations, additional documents concerning business values and logics, description of reverse logistics activities, sustainability and value considerations were collected. These documents ranged from being marketing materials, joint project management plans, terms and conditions of agreements, to even publicity documents available online. In particular there were a lot of online materials (e.g. posts, news and videos) available on the retailers, charities and commercial recyclers. Communication activities via websites and other media coverage were also retrieved where necessary.

\subsection{Data analysis}

Overall, the analysis has followed a qualitative content analysis procedure labelled "directed content analysis" (Hsieh \& Shannon, 2005), in which a selection of a priori developed concepts guided the analysis. Evidences collected from multiple data sources - both primary and secondary - were analyzed in accordance to a set of principles (Miles and Huberman, 1994). First, the coding, writing and sorting of data were formalised. This was carried out by first carefully reading through all transcriptions, notes and news and marketing materials. The authors thereafter jointly created a tabulated sheet with an index of the codes consistent with the matrix presented in Table 2 (see next chapter), focusing on, for each category of supply chain member, (1) the main processes for creation of use value, (2) the types of value created and their target, and (3) the value appropriation mechanisms. As a second step, within each cell in the matrix, the authors together in dialogue further sub-categorised and extracted key phrases regarding the content. After the coding exercise, a summary was written for each type of supply chain member (i.e. retailers, charity organisations, commercial recyclers, and specialised sorting companies), by one of the authors that was later approved by the others. This summary is the basis for what is presented as empirical data in the next chapter. 


\subsection{Research quality}

As a means to ensure the legitimacy of the findings, this research has adopted the framework of credibility, transferability, dependability and confirmability elaborated by Halldorsson \& Aastrup (2003). This framework is based on an interpretivist research approach, and is according to the authors particularly suitable for "soft", qualitative logistics research as this research represents. Credibility, similar to internal validity (Yin, 2009) has in this research been ensured through control and follow-up questions and careful separation of key constructs (such as value creation and appropriation) during the research process in order to facilitate understanding of causal relationships in the data (Ellram, 1996). Transferability of the findings corresponds to external validity. In order to enable a critical understanding of the reader, and thus ability to judge the generalizability of the research (Gibbert et al., 2008), the findings has been contextualised and descriptions of the members of the reverse clothing supply chain has been included. Dependability, closely related to reliability, has been ensured through a relatively narrow focus on the value creation and appropriation processes during the data collection. Although slight changes occurred in the interview guide due to different informant's expertise and focus, the interview guide has also been kept with few alterations. In addition, data triangulation strategies such as overlapping data information gathering at the different points of data collection have been adopted. Finally, confirmability, related to the conventional view of objectivity, has been obtained by "a chain of evidence" (Gibbert et al., 2008; Yin, 2009) between the interview transcripts, the case descriptions, the value concept (i.e. the theoretical foundation of this research) and findings.

\section{Findings and analysis}

An overview of the reverse clothing supply chain is shown in Figure 1. The following sections are structured into the four categories of supply chain members investigated in the study. For each category, the main processes for creation of use value, the types of use value created and their target, and the value appropriation mechanisms, are discussed.

Figure 1: An overview of the reverse clothing supply chain

Please insert Figure 1 here

\subsection{Retailers}

Retailers in Sweden have a long tradition of being engaged in take-back schemes of used clothes. Beside unmanned collection boxes at waste disposal sites, which is by far the most common collection alternative in Sweden for used clothes, boxes located within the retailers' stores provide excellent, convenient collection places. Organised by the retailers themselves or in collaboration with recyclers or charity organisations this collection process and the subsequent storing and distribution processes create value in the form 
economic value (typically clothes that can be sold or remanufactured). In addition to used clothes, retailers also occasionally donate new clothes directly to charity organisations. New clothes followed by high quality fashion branded clothes are given higher economic value for the recyclers as well as the charity organisations, as these products can directly be sold again to a relatively high price.

In terms of exchange value, the study shows that there are situations where the retailers get paid for the clothes (often price per kilo) as well as situations when the retailers pay or take extra costs for the collection of clothes, for instance by providing the customers with a voucher when handing in used clothes and taking care of the transportations of the used clothes. In strict monetary terms the retailers normally strives for a zero-sum game. On the one hand, when the costs are too high, they tend to negotiate that involved costs should be taken by the receiving organisations. On the other hand, if the retailer makes profit, the surplus is normally donated for charitable or other social activities. As witnessed by the retailers interviewed in this study, a major reason for this is to avoid suspicions of being engaged in take back schemes for profit making reasons.

The key incentive for retailers to engage in take back schemes is instead the possibility to create (and capture) values beyond economic ones. Use value for the retailers themselves in the form of environmental value as well as customer value is enhanced due to improved sustainability image towards consumers. As such, the retailers expect this image to improve their long term customer loyalty. Engagement in actions undertaken towards decreased environmental damage (such as being involved in take-back schemes) is thought to improve the retailers' environmental image and increase customer satisfaction as customers are offered to buy and wear clothes produced by an environmentally friendly, responsible company. Such a sustainability image is slowly becoming a source for competitive advantage for the fashion retailers (Hvass, 2014).

A major mechanism for capturing both environmental and customer values is advertising, that demonstrates the retailers' involvement in the collection process. For example both the retailers interviewed in this study, and also few other competing retailers, organise specific collection campaigns and issue purchasing vouchers for new clothes against handing of old clothes by end consumers. Common for these efforts is that the sustainability image created in the reverse supply chain should be associated with the retailers.

\subsection{Charity organisations}

Important partners for many retailers involved in take back schemes are charity organisations. In common for these organisations is their interest in being involved in the reverse clothing supply chain as a means to make monetary profit that can be used mainly for charity activities, but also be able to directly donate clothes to people in need. Processes fundamental for creation of economic value vary among different charity organisations, but span normally from collection, sorting, remanufacturing, and sales of clothes (acting as second-hand retailers but also as a wholesaler to recycling companies or specialised sorting companies further upstream in the supply chain). A key ingredient for achieving economic value is cost efficient, smooth collection and sorting processes. In particular cost efficiency in the sorting process, nowadays often executed as a welldefined, standardised professional working process, have been stressed in previous research studies in the Swedish market (Carlsson et al. 2015). The interviewees are well aware of the importance of "finding" and "extracting" the value from the waste clothes during the sorting process, indicating that in their mind, used clothes contain hidden, 
latent value that can be illuminated. Therefore, the charity organisations included in this study put a lot of effort in education of their sorting personnel in terms of quality and fashion trends as a means to improve the outcome (i.e. effectiveness) of the sorting process. This is for instance done in collaboration with the Swedish Fashion Council. Apart from recapturing latent, hidden value (see Rogers \& Tibben-Lembke's definition above), "new" economic value is also created during remanufacturing and repair processes in both charities included in this study. Although these processes are costly, i.e. there is a high opportunity cost, the willingness-to-pay also increase according to the interviewees, which means that higher exchange values can be achieved (Brandenburger \& Stewart, 1996). In particular "high-street fashion customers" are here targeted, looking for unique, personal products, typically branded, vintage clothes of high quality. The price for this customer category is less important and economic value surplus can therefore be enhanced. In addition, the remanufacturing and repair processes create customer value when offering unique, personal product offering that goes hand in hand with overall fashion trends where uniqueness and exclusivity are decisive factors (Young et al., 2004).

Considering the charity organisations' value appropriation, they are experiencing an increased competition in the reverse clothing supply chain both regarding donation of clothes as well as sales in their second-hand stores. For instance, according to the interviewees, there have been increased advertising efforts in recent years, by the retailers involved with take back schemes to attract consumers in the market. Bargaining efforts towards recyclers (that are competitors but also customers to the charities) have also been more fierce in recent years and relationships have been less collaborative. In times of more competition, the charity organisations have also had to develop themselves rapidly in recent years. New customer type such as the high street customers has been targeted by special vintage shops with high-quality clothes, sometimes remanufactured and repaired by the charity organisations. This type of customers is less price-sensitive and (monetary) value appropriation is here more easily achieved for the charity organisations.

\subsection{Commercial recyclers}

Beside charity organisations, there are also a number of large, international, commercial recycling companies in the market who often works in close partnership with the retailers. The commercial recyclers constitute a comprehensive, convenient partnership alternative to the retailers, managing a wide range of processes related to the reverse supply chain, including collection of donated products, sorting and further distribution/sales to other members of the reverse supply chain, as well as supply of recycled textile fibres that are offered to the retailers' producers.

In order to create economic value, the interviewees from the commercial recyclers consider their overall task to be about matching supply (i.e. donated clothes collected in collaboration with retailers) with demand from a wide range of other international players such as specialised sorting companies (discussed here below) and producers in need of recycled material. Representative for this matching process is above all (1) knowledge and relationship building with retailers, (2) efficient sorting of collected clothes into all levels of the waste hierarchy (Carter \& Ellram, 1998), and (3) contacts and ability to merge clothes and ship containers to suitable sorting companies, producers and other customers. Overall, the role of the commercial recyclers is similar to that of the intermediaries referred in marketing channel literature (Stern \& El-Ansary, 1988). Stressing the need for a value creating role of each included supply chain member 
(Kozlenkova et al., 2015), the commercial recyclers create economic value for members on both sides in the supply chain by overcoming gaps related to e.g. time, place and information (Stern \& El-Ansary, 1988). In addition to economic value, the commercial recyclers also create environmental value for the retailers. According to the commercial recyclers interviewed in the study, a major incentive for retailers to partnering them is their environmentally friendly life-cycle approach in their business, attractive for end consumers.

The recyclers' major advantage in order to appropriate economic value is information asymmetry, utilised as a source for bargaining power (Rehme et al., 2015). For instance, as witnessed by one of the interviewees, their global presence and size means that they are able to monitor the fragmented, global market of used clothes and provide smaller, more specialised sorting companies with suitable material. Beside information asymmetry the recycling companies are also able to offer a more complete offering towards retailers compared to charity organisations, particularly including supply of recycled fibres.

\subsection{Specialised sorting companies}

Another profit-oriented member of the reverse clothing supply chain is the specialised sorting companies. Such companies are to be found in many locations around the world, in particular in regions with relatively low wages, as the sorting procedures are often accomplished manually. As argued in the methodology section, the Indian sorting companies investigated in this study serve as a representative.

All Indian sorting companies included in this study import used clothes mainly from commercial recyclers in the USA, Canada, and Europe. High degrees of dependence on advanced sorting processes, however manually executed, results in different fractions along the waste hierarchy (Carter \& Ellram, 1998). In terms of value creation, efficiency and effectiveness in these sorting processes is decisive for economic value creation for this type of member in the reverse supply chain. Their overall goal is to maximise the fraction of clothes that can be sold at the second hand market. These products generate a relatively high exchange value (in comparison to the outcomes from other fractions), thus yielding maximum opportunity for making profit for the sorting companies. In addition to sales of second hand clothes, other sorted and downcycled fractions results in sales of rags, mainly to Indian companies, also resulting in creation of economic value that is translated into exchange value when sold. Finally, besides creating economic value for themselves, clothes from some sorted fractions (not possible to be sold elsewhere) are also donated to charity organisations, particularly in Africa, hence creating economic value for the receiving organisations.

The Indian sorting companies appropriate value mainly through fierce price negotiation with the suppliers (e.g. commercial recyclers) as well as customers (e.g. second-hand retailers). Typically, waste clothes are considered as globally traded goods, sold at a spot market of containers (in bales), their content ranging from sorted to unsorted waste clothes where unsorted bales typically bring a higher price. The price is in turn an outcome of the bargaining power of involved supply chain members. Except for economic supply and demand mechanisms, which can vary over time in this industry, value appropriation for the Indian sorting companies included in this study are also determined by the fact that they must have a specific license for the trading of second hand clothes 
and are only allowed to operate in bounded economic zones. The objective of these licenses is to control trading of foreign clothes and protect domestic production (Brooks, 2013). At the moment 22 Indian companies holds such a license. The licenses partly outmanoeuvres the economic supply and demand mechanisms and could at least potentially in case of strong demand, be utilised by the Indian sorting companies as a weapon to appropriate more value. A summary of the findings are presented in Table 2 below.

Table 2: Summary of the findings

Please insert Table 2 here

\section{Conclusions and future research}

This research illustrates and details processes involved in the creation of use value, the type of use value created, and the value appropriation mechanisms applied among members of the reverse clothing supply chain. A fundamental, first value creation process involved is the collection process, typically conducted by retailers and/or charities or recyclers. This initial process is followed by a series of grading and sorting processes at different tiers of the supply chain. Finally, various supply and selling processes along the supply chain ensure that the collected clothes find appropriate receiving organisations or consumers. Beside these major processes additional activities such as logistics processes (e.g. handling, transportation and storing) occur at all stages in the supply chain.

The findings demonstrate that there are above all three major types of value created by these processes. First, a dominating use value created in the reverse supply chain is economic value, which is above all the major incentive for charities, international commercial recyclers, and specialised sorting companies to be involved in the reverse clothing supply chain. Through a series of grading and sorting processes, conducted by different supply chain members, sometimes complemented with remanufacturing/repair processes, economic use value from the waste clothes are extracted as well as created 4 . The higher the efficiency and effectiveness in these processes, the more value is created (Skinner et al., 2008; Fleischmann et al., 2004). The economic use value created is directly transformed into exchange value when the clothes are sold further in the supply chain. Except for economic values, environmental values are also created. The investigated members of the reverse supply chain together enable a reduction of the need for virgin materials that creates environmental value in the form of e.g. waste and energy savings (Watson et al., 2014). Except for improved overall environmental performance, environmental image value is also created. The retailers aiming at improving their sustainability image among consumers mainly obtain this value. As such, this

\footnotetext{
${ }^{4}$ As argued in the previous chapter, we note that except for extracting/recapturing latent, hidden value in the collected clothes, also "new" economic value can be created during remanufacturing and repair processes
} 
environmental image value also turns into a customer value as environmentally friendly alternatives drive customer satisfaction (Hvass, 2014).

In terms of value appropriation, retailers capture the environmental and customer values inherent in the reverse clothing supply chain by advertisements and campaigns in which end customers are appealed to be associated with fashion brands with strong sustainability profile. Frequent advertisements and campaigns by the retailers entail communication of the post-retail concepts, thus making end consumers associate this "image value" to them. Otherwise, among the members of the reverse clothing supply chain the dominant value appropriation mechanism is bargaining power, which in turn is based on a number of different sources. For instance, commercial recyclers have a relatively strong bargaining position due to their ability to provide specialised sorting companies with a smooth supply of products, in an industry otherwise characterised by spot market trade with volatile supply and demand. Another interesting example is that of the Indian sorting companies, which partly build their negotiation power on regulations and licences that reduce and obstruct competition.

Based on the findings of the value creation and appropriation processes, this study enables insight on the structure and relationships of the reverse clothing supply chain. From the findings it is evident that closer to donators and consumers, i.e. at the "beginning" of the reverse supply chain, more collaborative relationships dominate, whereas short-term arms-length agreements are more common further "upstream" in the reverse supply chain. It could be argued that the reason for this originates from the participants' appropriation of different types of values as well as the value co-creation mechanisms that are in place.

Regarding the different types of values appropriated, collaboration in the initial part of the supply chain outmanoeuvres the traditional value appropriation mechanism of price negotiation and bargaining, as is normally suggested by value literature. Simply put, as long as the collaboration partners are interested in different types of values, relatively little bargaining is seen at this part of the supply chain. As the participants' interests diverge, the relationships can be described as collaborative and based on a win-win thinking. This situation could be considered as a "value match" that provides excellent conditions for win-win-based collaborative relationships.

An example of value match at the very beginning of the reverse supply chain is the match between high-street fashion consumers on the one hand, and charity organisations on the other. The charities produce and sell unique, relatively expensive products as this type of consumers seeks the image and uniqueness of the products they buy. For the charities, this customer segment means relatively high profit margins, i.e. economic value can relatively easily be gained from these customers. Another example of a value match, perhaps the most striking one, is found between the retailers and the charity organisations. In terms of rationales for retailers to be involved in take back schemes and provide clothes to the charity organisations, these are mainly related to an ability of improving their image and, ultimately, trust from consumers. As a result, retailers appropriate environmental and customer image value related to the reverse clothing. Meanwhile, the charity organisations (and commercial recyclers) secure clothes and economic benefits for their charity operations.

The value match also means that the retailers and their partners have mutual incentives for collaboration, which fosters excellent conditions for value co-creation to occur (Saarijärvi et al., 2013). In particular the collection process is here an example of value co- 
creation, where a convenient collection place provided by the retailers, is combined with the physical handling and management of the take-back schemes conducted by the charities (and commercial recyclers). Value is here to be considered as co-created, as the supplier (retailer) here offers a collection place, that is fully exploited and combined by the resources of the customer (in this case the charity organisation or recycler). As such, the value co-creation here results in a mutual dependence that fosters collaboration in the supply chain.

The retailers' appropriation of image value through advertisements and campaigns is also an example where synergies are enhanced between the two processes of value creation and appropriation. By communication towards end consumers drawing on sustainability and uniqueness, retailers are capturing existing environmental and customer value in the supply chain. At the same time, the more advertisement and other communication efforts towards end customers, the more of these values are created, as they are continuously fed and reinforced by the advertising and campaigns in the collection and sales processes.

Another finding of the study is that the value concept emphasises the relatively great share of commercial interests involved in the reverse clothing supply chains. Interviewees witnessed poor knowledge and understanding among the end consumers (and donators) regarding the business mechanisms and the structure of the entire reverse clothing supply chain. Similar conclusions were also drawn in a British study on the international second-hand clothing trade (Brooks, 2013). One reason for this might be the collaborative relationships and value match that dominate close to the donators (i.e. consumers) in the reverse supply chain. The façade towards donators of the entire reverse clothing supply chain as a pure charity and sustainability project could be fuelled by retailers eager for improved image, respectively charity organisations that want to ensure future access to donated clothes. In reality, as this study and the study conducted by Brooks (2013) clearly demonstrate, the reverse clothing supply chain is to a large extent commercial. Here for instance global commercial recyclers with their main objective of financial profit making have been investigated in this study. Another important group of supply chain members not investigated in this study, but in Brooks' (2013) study, is profit making retailers in developing countries receiving second hand clothes. Brooks (2013) concludes from his study that an overwhelming amount of the collected clothes by charity organisations in developed countries are retailed for profit by local players in the developing countries.

In terms of contribution, this research advances the understanding of a reverse supply chain and its members. For practitioners, the results from this study emphasise that there is a need for an understanding of potential partners' motives and interests for different types of values created. Interaction among different supply chain members is necessary as a means to enhance competitive advantage and customer satisfaction. A value perspective, with clearly outspoken objectives when it comes to types of values created and how these values are captured among the supply chain members, may facilitate an improved overall supply chain performance. In terms of theoretical contribution, anchored in the value concept, this research illuminates the rationale behind a certain supply chain structure in terms of incentives for participating supply chain members and type of relationships involved.

This explorative research suffers from a number of limitations, and the results of this study should be tested and developed in more rigorous studies in the future. For instance, given the wide scope of supply chain member categories covered, as well as processes included in the study, means that in-depth understanding of particular circumstances or 
activities have not been elaborated in full in this research. One example is the lack of quantitative environmental performance measurements. As environmental performance is often achieved at a supply chain level (Hvass, 2014), in depth studies of specific reverse supply chains with connected companies would be needed to capture and quantify such performance. Another limitation of the study is its focus on specific regions, even though representative such as the Swedish and Indian contexts, which may hamper the generalizability of the findings presented here. For instance, the specialised Indian sorting companies involved in this study have competitors in Eastern Europe as well as other regions in Asia. Another limitation has been the ignorance of time and duration of partnerships explored in the empirical data.

As such, the limitations also feed into a number of viable future research topics. In particular, we see three important research avenues. First, in a discussion of value creation (and appropriation) it is important to consider not only value for customers as is often in focus when explaining the foundations of the value concept (Lepak et al., 2007; Brandenburger \& Stuart, 1996). Lepak et al. (2007) claim that a widened stakeholder perspective should be taken in order to fully understand values created. This research has incorporated a number of key players in the supply chain of the entire reverse clothing supply chain, and as a result value creation and appropriation processes among several stakeholders in the supply chain have been explored. However, other important stakeholders, and how they influence the supply chain in terms of value creation and appropriation, have been outside the scope of this study. For instance, from an environmental perspective (Kim \& Lee, 2012), customers, employees, shareholders, governments, and society/nongovernmental organisations are all important stakeholder categories that put pressure on the reverse clothing supply chain. Regulatory bodies and government, typically associated with coercive pressures, have so far got most attention in research (Sarkis et al., 2010; Kim \& Lee, 2012). However, in the context of reverse clothing supply chains, another influential stakeholder category is the consumer. Creation of customer value in the form of environmental image is in this research identified as a major incentive for retailers' participation in reverse clothing supply chains. Another major stakeholder category in reverse logistics is employees, in particular policy entrepreneurs who drive the development forward and overcome barriers (e.g. Carter \& Ellram, 1998). Combining the value concept with a stakeholder theory perspective (e.g. Sarkis et al., 2010) that incorporates diverse stakeholder categories would strengthen and explain these findings further.

Second, taking a resource-based perspective on the reverse clothing supply chain, the value creation and appropriation processes require that relevant resources and capabilities exist. Earlier research has for instance acknowledged that acquisition processes including convenient collection channels for households may not always be in place hence obstructing effective value creation (O'Reilly \& Kumar, 2016). It is assumed that for these processes, a suitable set of resources and capabilities is needed in order to successfully carry them out. These resources and capabilities however still remain to be explored. Overall, so far strategic management research including for instance the perspectives of a business model and a resource-based view of the firm has been neglected in this type of research and deserves more attention in the future.

Third, this study along with other studies such as Brooks (2013) may work as an initial step towards more detailed research on Corporate Social Responsibility (CSR) in a reverse supply chain setting. For retailers as well as other members of the traditional, "forward" supply chain (Fleischman et al., 2004), involvement in the reverse supply chain 
of used clothes could be considered as a complement to the previous, more established, upstream CSR and sustainability efforts. To focus on the end-of-life phase of the products could be seen as a logical next step in many companies' sustainability agendas (Hvass, 2014; Jayaraman \& Luo, 2007). However, as a relatively immature industry, but globally stretched, with a large portion of manual labour in low cost countries (Gereffi \& Frederick, 2010), the reverse clothing supply chain contains many challenges related to CSR. Although outside the scope of this study, the findings suggest a need for future in-depth studies of adoption of CSR practices in the reverse supply chain setting, including e.g. code of conducts applied to a reverse supply chain setting, and alignment and synergies with practices in the traditional, "forward" supply chain.

\section{References}

Acharya, N. (2015), "India emerges top importer of used clothes", Business Standard, Kolkata, 10 October, accessed 120417, http://www.businessstandard.com/article/current-affairs/india-emerges-top-importer-of-used-clothes115100800540 1.html.

Bernon, M., Rossi, S. and Cullen, J. (2011), "Retail reverse logistics: a call and grounding framework for research", International Journal of Physical Distribution \& Logistics Management, Vol. 41 No. 5, pp. 484-510.

Botticello, J. (2012), "Between Classification, Objectification, and Perception: Processing Secondhand Clothing for Recycling and Reuse", Textile, Vol. 10 No. 2, pp. 164-183.

Bowman, C. and Ambrosini, V. (2000), "Value creation versus value capture: Towards a coherent definition of value in strategy", British Journal of Management, Vol. 11, pp. 1-15.

Brandenburger, A, M. and Stuart, H W. (1996), "Value-Based Business Strategy", Journal of Economics \& Management Strategy, Vol. 5 No. 1, pp. 5-24.

Brooks, A. (2013), "Stretching global production networks: The international secondhand clothing trade", Geoforum, Vol. 44, pp. 10-22.

Carlsson, J., Torstensson, H., Pal, R. and Paras, M. (2015), “Re:Textile - Planning a Swedish Collection and Sorting Plant for Used Textiles", accessed 210417 at http://www.divaportal.org/smash/record.jsf?dswid=531\&pid=diva2\%3A916826.

Carter, C. and Ellram, L. (1998), "Reverse logistics: a review of the literature and framework for future investigation”, Journal of Business Logistics, Vol. 19 no. 1, pp. 85-102.

Cova, B., Dalli, D., and Zwick, D. (2011), "Critical perspectivesis. consumers' role as 'producers': Broadening the debate on value co-creation in marketing processes", Marketing Theory, Vol. 11 No. 3, pp. 231-241.

Cox, A. (1999), "Power, value, and supply chain management", Supply chain management: An International Journal, Vol. 4 No. 4, pp. 167-175.

Eisenhardt, K. (1989), "Building theories from case study research", The Academy of Management Review, Vol. 14 No. 4, pp. 532-550.

Ekström, K., and Salomonsson, N. (2014), "Reuse and Recycling of Clothing and Textiles A Network Approach", Journal of Macromarketing, Vol. 34 No. 3, pp. 383-399. 
Ellram, L.M. (1996), "The use of the case study method in logistics research", Journal of Business Logistics, Vol. 17 No. 2, pp. 93-138.

Fleischmann, M., Nunen, J. Gräve, B. and Gapp, R. (2004), "Reverse logistics - Capturing value in the extended supply chain", ERIM Report Series Research in Management, ERS2004-091-LIS

Flyvbjerg, B. (2006), "Five misunderstandings about case study research", Qualitative Inquiry, Vol. 12 No. 2, pp. 219-45.

Gereffi, G., and Frederick, S. (2010), "The Global Apparel Value Chain, Trade and the Crisis: Challenges and Opportunities for Developing Countries." The World Bank - Development Research Group.

Gibbert, M., Ruigrok, W., and Wicki, B. (2008), "What passes as a rigorous case study?" Strategic Management Journal, Vol. 29 No. 13, pp. 1465-1474.

Halldorsson, A. and Aastrup, J. (2003), "Quality criteria for qualitative inquiries in logistics", European Journal of Operational Research, Vol. 144 No. 2, pp. 321-332

Hsieh, H-F. and Shannon, S. (2005), "Three approaches to qualitative content analysis", Qualitative Health Research, Vol. 15 No. 9, pp. 1277-1288.

Hvass, K. (2014), "Post-retail responsibility of garments - a fashion industry perspective", Journal of Fashion Marketing and Management, Vol. 18 No. 4, pp. 413-430.

Jack, E., Powers, T. and Skinner, L. (2010), "Reverse logistics capabilities: antecedents and cost savings", International Journal of Physical Distribution \& Logistics Management, Vol. 40 No. 3, pp. 228-246.

Jayaraman, V. and Luo, Y. (2007), "Creating Competitive Advantages Through New Value Creation: A Reverse Logistics Perspective”, Academy of Management Perspectives, Vol. 21 No. 2, pp. 56-73.

Kim, S. and Lee, S. (2012), "Stakeholder pressure and the adoption of environmental logistics practices", The International Journal of Logistics Management, Vol. 23 No. 2, pp. 238-258.

Klassen, R. (2009), “Comment on “'The Evolution of Closed-Loop Supply Chain Research' by V. Daniel R. Guide, Jr. and Luk N. Van Wassenhove", Operations Research (online forum commentary), Vol. 57 No. 1, pp. 1-3.

Kozlenkova, I., Hult, T., Lund, D. Mena, J. and Kekec, P. (2015), "The role of marketing channels in supply chain management", Journal of Retailing, Vol. 91 no. 4, pp. 586-609.

Lavie, D. (2007), "Alliance portfolios and firm performance: A study of value creation and appropriation in the U.S. software industry", Strategic Management Journal, Vol. 28 No. 12, pp. 1187-1212.

Lepak, D., Smith, K. and Taylor, S. (2007), "Value creation and value capture: A multilevel perspective”, Academy of Management Review, Vol 32 No. 1, pp. 180-194.

Mizik, N. and Jacobsen, R. (2003), "Trading off between value creation and value appropriation: The financial implications of shifts in strategic emphasis", Journal of Marketing, Vol. 67 No 1, pp. 63-76. 
Mollenkopf, D., Russo, I. and Frankel, R. (2007), "The returns management process in supply chain strategy", International Journal of Physical Distribution \& Logistics Management, Vol. 37 No. 7, pp. 568-592.

O’Reilly, S. and Kumar, A. (2016), "Closing the loop: An exploratory study of reverse readymade garment supply chains in Delhi NCR", International Journal of Logistics Management, Vol. 27 No. 2. Pp. 486-510.

Palm, D., Elander, M., Watson, D., Kjorboe, N., Salmenperä, H., Dahlbo, H., Moliis, K., Lyng, K.-A., Valente, C. Gislason, S. Tekie, H. Rydberg, T. (2014), "Towards a Nordic textile strategy - Collection, sorting, reuse and recycling of textiles" TemaNord 2014:538, ISBN 978-92-893-2794-7.

Rehme, J., Nordigården, D., Ellström, D. and Chicksand, D. (2015), "Power in distribution channels - Supplier assortment strategy for balancing power", Industrial marketing management, Vol. 54, pp. 176-187.

Rogers, D. and Tibben-Lembke, R. (2001), "An examination of reverse logistics practices", International Journal of Logistics Management, Vol. 22 No. 2, pp. 129-148.

Saarijärvi, H., Kannan, P.K., and Kuusela, H. (2013), "Value co-creation: theoretical approaches and practical implications", European Business Review, Vol. 25 No. 1, pp. 6-19.

Sarkis, J., Gonzalez-Torre, P. and Adenso-Diaz, B. (2010), "Stakeholder pressure and the adoption of environmental practices: the mediating effect of training", Journal of Operations Management, Vol. 28 No. 2, pp. 163-76.

Schenkel, M., Caniëls, M., Krikke, H. and van der Laanc, E. (2015), "Understanding value creation in closed loop supply chains - Past findings and future directions", Journal of Manufacturing Systems, Vol. 37 No. 3, pp. 729-745.

Skinner, L., Bryant, P. and Richey, G. (2008), "Examining the impact of reverse logistics disposition strategies", International Journal of Physical Distribution \& Logistics Management, Vol. 38 No. 7, pp. 518-539.

Stern, L and El-Ansary, A. (1988), Marketing channels, ( $3^{\text {rd }}$ ed.), Prentice-Hall International Editions, London, ISBN 0-13-556820-X.

Wacker, J.G. (1998), "A definition of theory: research guidelines for different theorybuilding research methods in operations management", Journal of Operations Management, Vol. 16 No. 4, pp. 361-385.

Watson, D., Kiørboe, N., Palm, D., Tekie, H., Harris, S., Ekvall, T., Lindhqvist, T. and Lyng, K. (2014), "EPR systems and new business models: Reuse and recycling of textiles in the Nordic region", TemaNord 2014:539, ISBN 978-92-893-2796-1

Yin, R.K. (2009), Case study research: Design and methods, (4th ed.). Sage Publication, London.

Young, C., Jirousek, C. and Ashdown, S. (2004), "Undesigned: a study in sustainable design of apparel using post-consumer recycled clothing", Clothing Textile Research Journal, Vol. 22 No 1-2, pp. 61-68. 


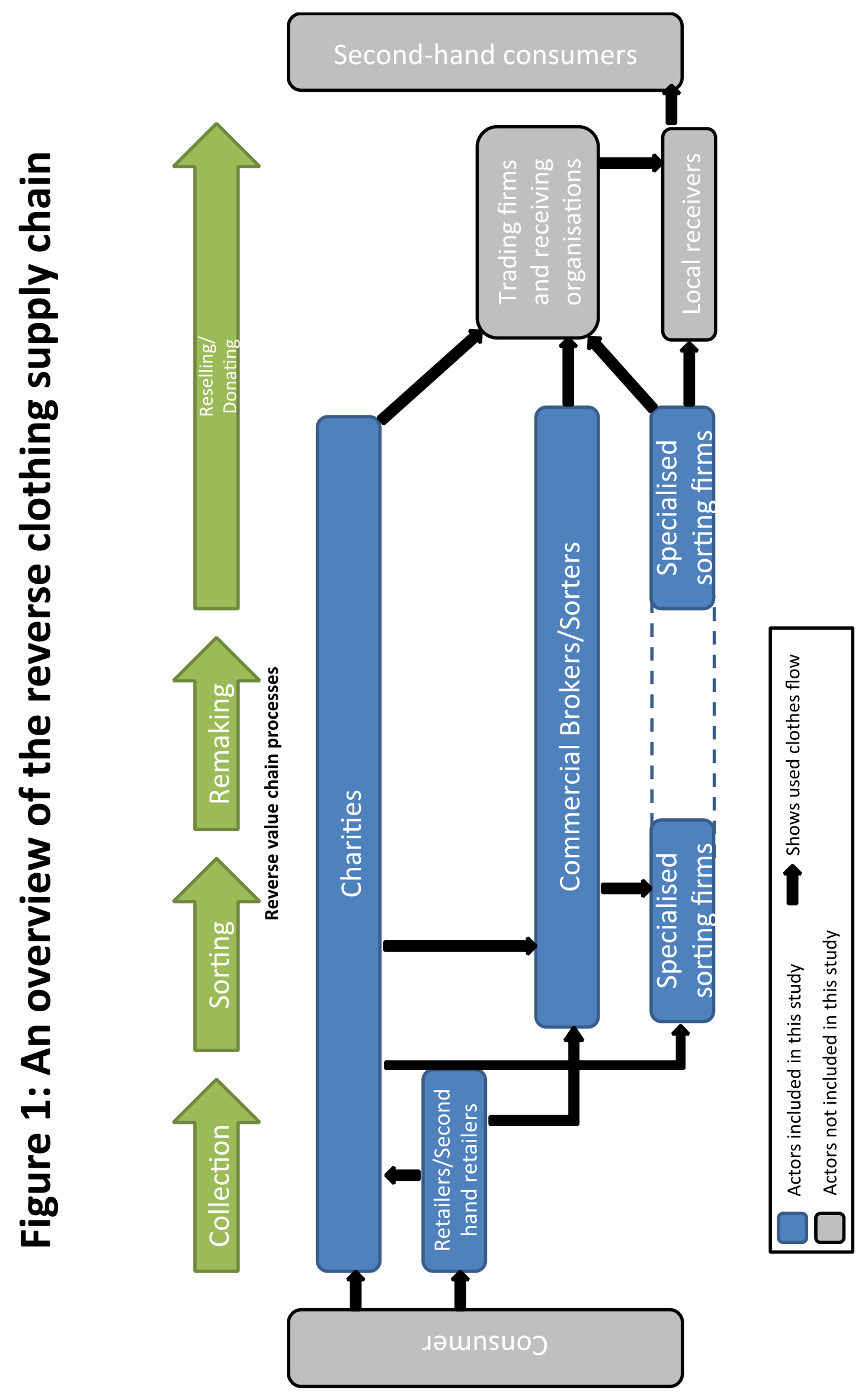


$\frac{\tilde{\alpha}}{\frac{0}{0}}$ 


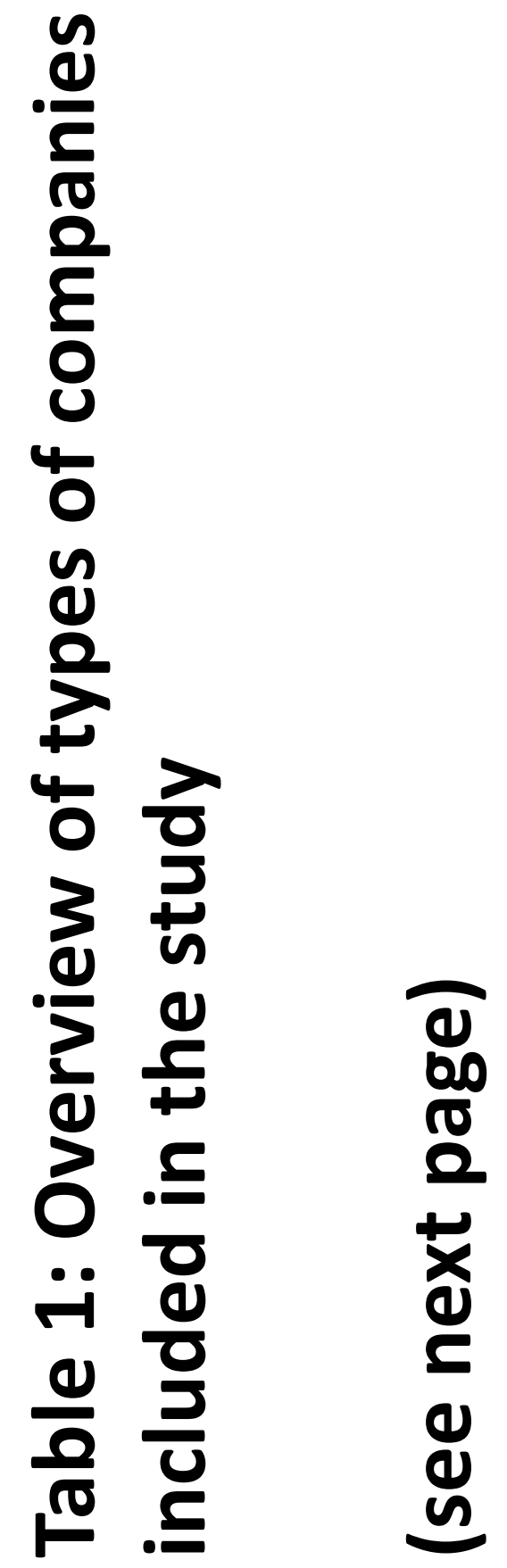




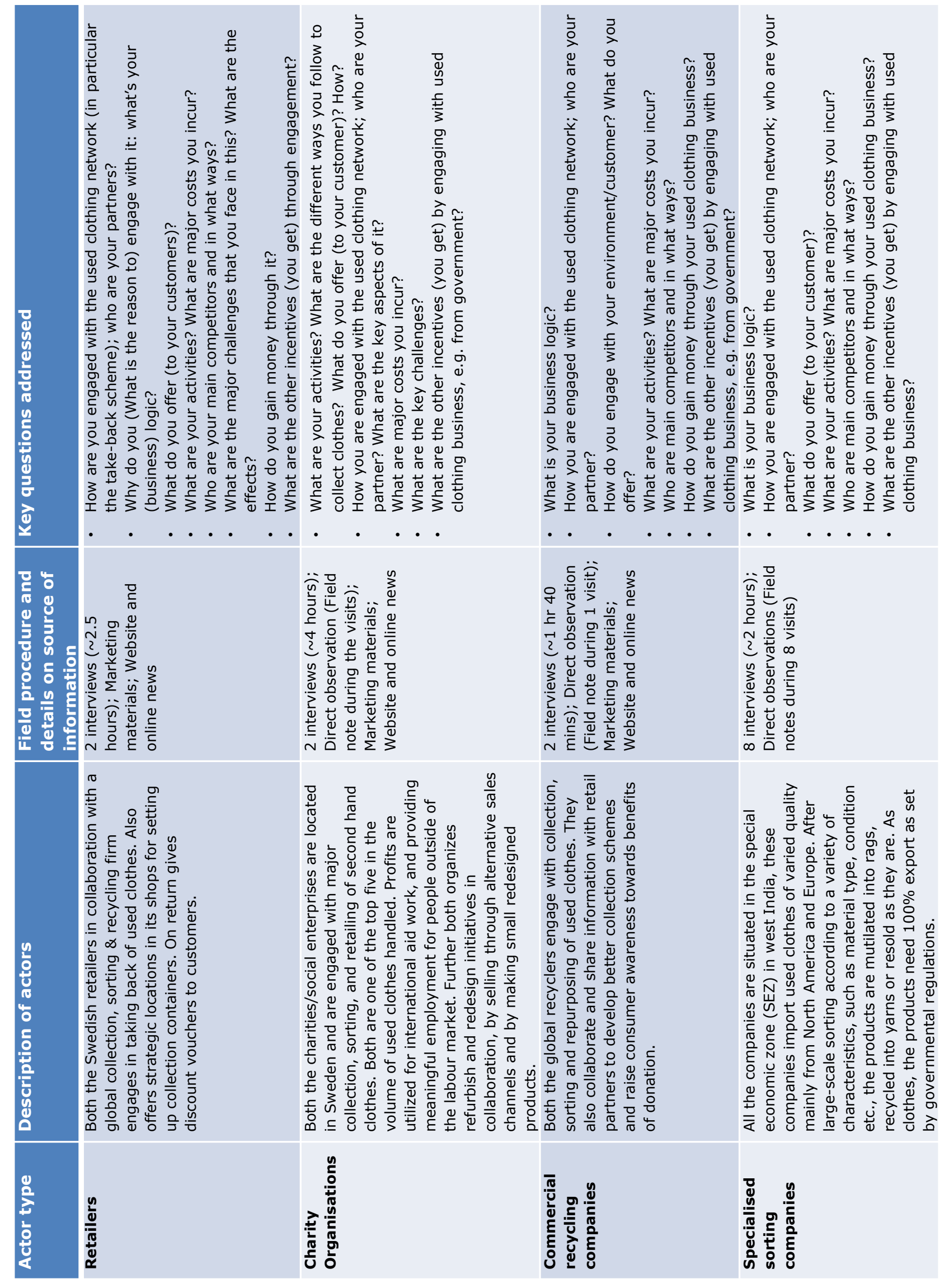




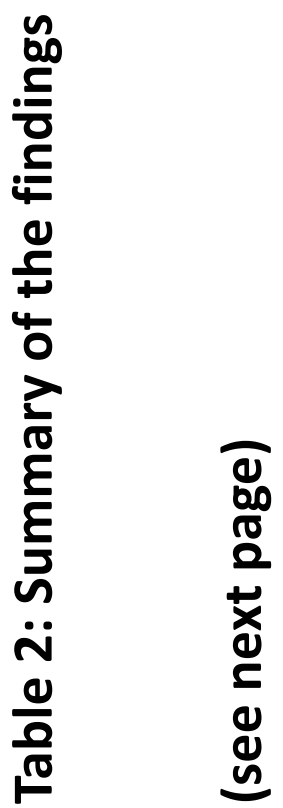




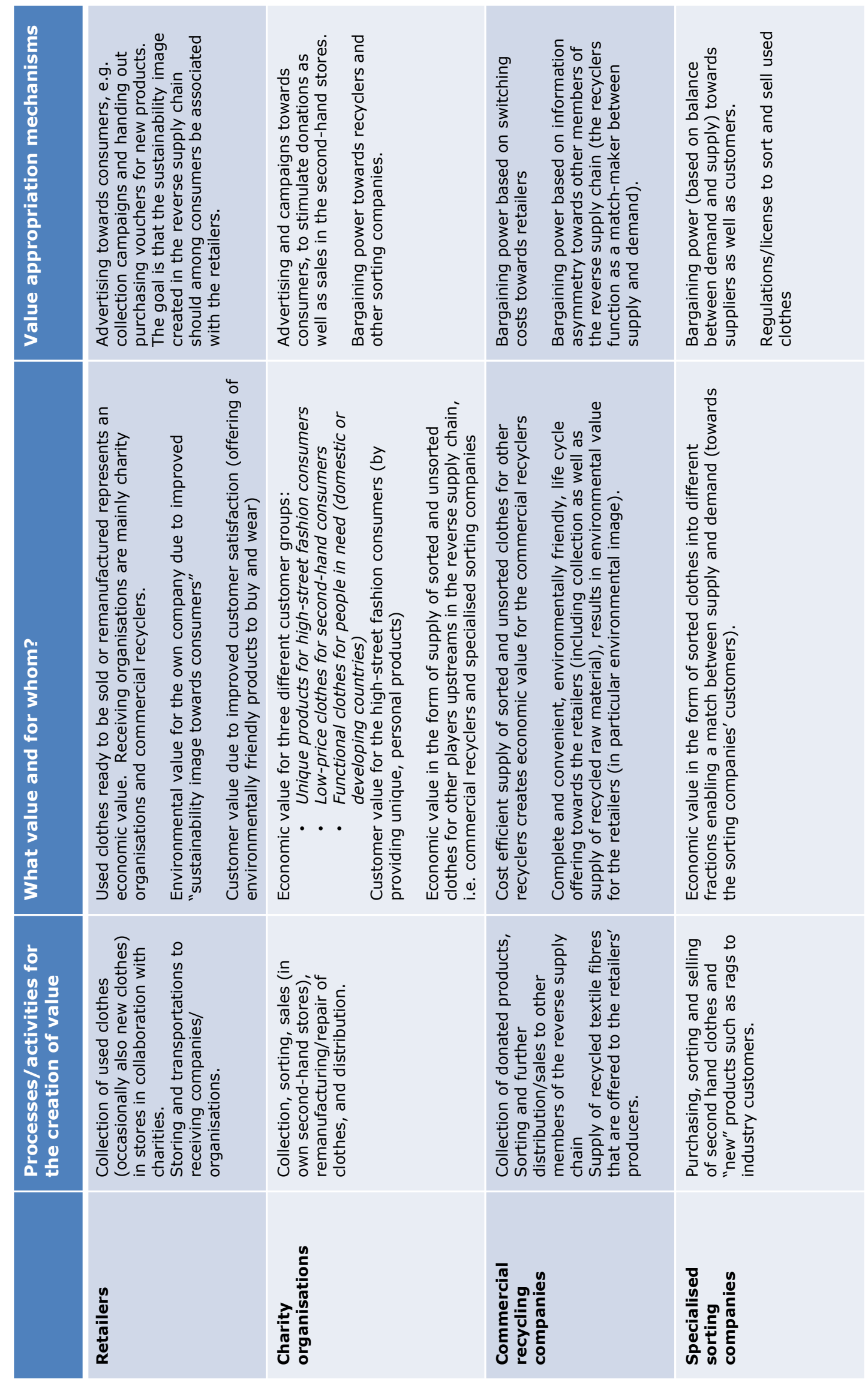

